\title{
International Research on Translation Teaching: A Review (2008-2017)
}

\author{
Xue Li \\ School of Foreign Languages, Nanjing University of Posts and Telecommunications, Nanjing, China
}

\begin{abstract}
This paper generally reviews the situation of international translation teaching research from five perspectives: research trends, subjects, contents, research nature, and the authors' disciplinary backgrounds. The results indicate that: (1) on the whole, the number of papers published steadily increases; (2) the undergraduates majoring in translation take up a dominant percentage of the subjects; (3) the content focuses on thematic research and applied research; (4) speculative research are accounting for the main part in methodology, in which literature method is usually employed as research instrument; (5) the authors' academic backgrounds mainly focus on the fields of linguistics and translation, presenting a multi-disciplinary feature. Finally, the characteristics and development trends of international translation teaching and research are summarized and enlightened.
\end{abstract}

Index Terms - translation teaching, international research, review and future prospects

\section{INTRODUCTION}

International translation teaching began in the 1930s. The Moscow Language University took the lead in opening a translation course in 1930 (Sachinis, 2011). Translation teaching originated from the language courses (for instance, Latin, Spanish and Greek) in European and American countries, and it belongs to auxiliary tools of language learning. Applying translation to language teaching is bound to be related to grammar translation method. Grammar translation method was first used in a Prussian middle school in the late eighteenth Century (Vermes, 2010). In a very long period of history, the research of translation teaching is only a subsidiary product of language teaching study. By 1950, the Soviet scholars had first put forward the theory and methods of translation teaching.

This paper reviews and analyzes translation teaching research internationally from five dimensions: research trends, subjects, contents, research nature and authors' discipline backgrounds. It summarizes the characteristics of overseas research and looks forward to future trend.

\section{RESEARCH TREND}

This research is based on EBSCOhost, Elsevier SDOS, SpringLink, Willy-Blackwell and Google academic search and electronic databases, choosing "teaching translation, translation teaching, pedagogical translation, translation learning, EFL translation, translation curriculum, translation course" as keywords, to finally retrieve 575 related articles in 2008-2017. We have counted the distribution and general trend of the articles on translation teaching abroad in the past decade (see Fig. 1).

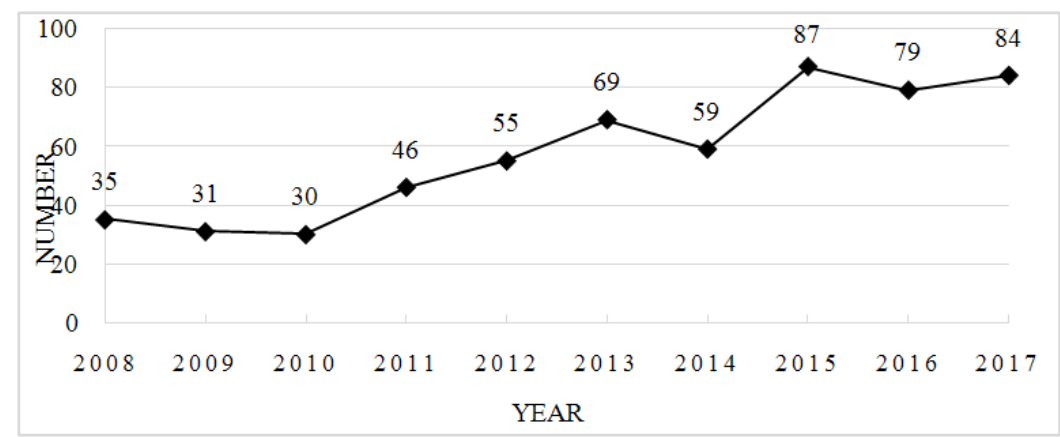

Figure 1. General Trend

Fig. 1 shows that the study of international translation teaching research can be divided into two stages. During 2008-2015, the number of articles has been increasing slowly, reaching a peak to 87 in 2015. In 2010, there is only 30 articles, being the lowest in ten years. During 2015-2017, the number of articles has changed less, and the basic stability is about 80. It can be seen that the study of international translation teaching shows a trend of dynamic development.

\section{SUBJECTS}


It is found that the subjects cover six continents, 63 countries and regions, including North America (such as Canada, the United States, Mexico), South America (Brazil), Europe (including Russia, Germany, Romania, Spain, Italy, UK), Oceania (such as Australia, New Zealand), Asia (such as Japan, Saudi Arabia, Thailand, Iran, China) and Africa (such as Cameroon, Libya and South Africa).

Fig. 2 is the countries in top ten in international translation teaching research from 2008 to 2017. It shows that the distribution of national publication volume is uneven, Iran and Spain being prolific countries, accounting for 1/4 of the total. It is worth mentioning that the number of articles of translation teaching research in China ranks the third, up to 41 , accounting for $7.13 \%$, which indicates that our research in this field has certain international influence.

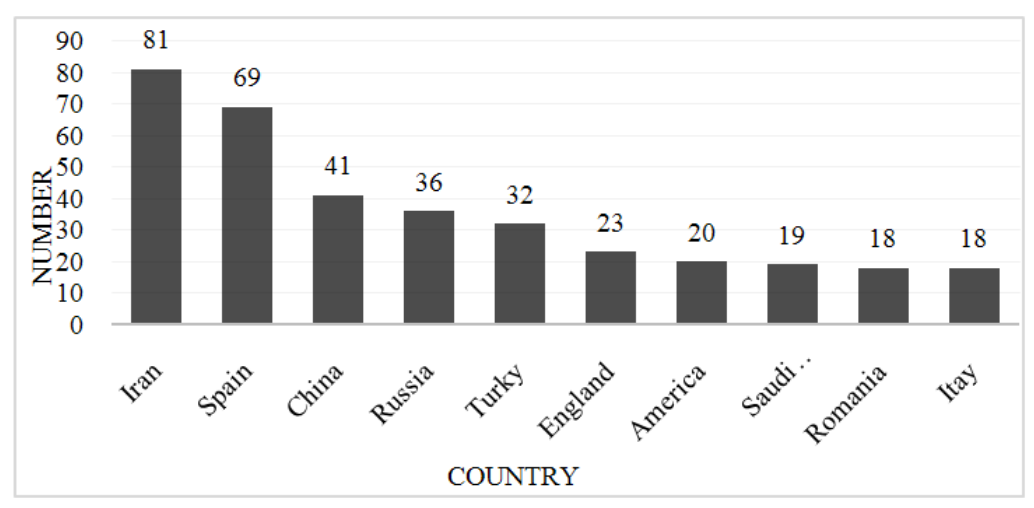

Figure 2. Top Ten Countries

In addition to the statistics on the geographical distribution of translation teaching research, we also explore the level of research subjects. The specific distribution and its ratio are shown in TABLE 1.

TABLE 1

RESEARCH SUBJECTS

\begin{tabular}{llll}
\hline Research Subjects & Number & \% \\
\hline & Undergraduates & 219 & 38.09 \\
\cline { 2 - 4 } & Undergraduates & 75 & 13.04 \\
\cline { 2 - 4 } Internal & Undergraduates \& Undergraduates & 29 & 5.04 \\
\cline { 2 - 4 } Students & Middle School Students & 2.26 \\
\cline { 2 - 4 } & Pupils & 13 & 0.52 \\
\cline { 2 - 4 } & Vocational students & 3 & 0.52 \\
\cline { 2 - 4 } & Doctoral Students & 3 & 0.52 \\
\hline Translators & & 3 & 19.30 \\
\hline Teachers & & 111 & 3.48 \\
\hline Adult Learners & 20 & 1.91 \\
\hline Teachers \& Students & 11 & 1.57 \\
\hline Others & & 9 & 13.74 \\
\hline Total & 79 & 100 \\
\hline
\end{tabular}

According to TABLE 1, the research subjects of this study are mainly internal students. Among them, undergraduates takes major part, with 219 related articles, accounting to 38.09\%. It pays a little attention to vocational students, doctoral students, middle school students and primary school students. On the other hand, from the geographical point of view, Iran and Spain publish predominant literature in this field.

It is worth mentioning that international researchers specially study the doctoral students in translation teaching research. For instance, Sidorenko, et al. (2016) investigates the needs of doctoral graduates and the curriculum contents of foreign language teaching in the doctoral program, and finally proposes the necessity to incorporate translation practice into Ph.D. English technical translation courses. In addition, for primary learners such as primary and middle school students, international research focuses on the impact of translation on their basic language skills (listening, speaking, reading, and writing), for example, Rokhshad \& Ranjbar (2016) conducts an experimental teaching of English translation of Persian stories to primary school students, in order to explore the influence of Persian story translation on Iranian learners' oral ability. The results shows that the oral ability of students receiving English translation tasks improve significantly in the experimental group, and the oral expression ability was significantly better than that of the control group.

\section{RESEARCH CONTENT}

It is found that the content of international translation teaching can be roughly divided into eleven categories: applied research, thematic research, investigating research, relevance research, ESP research, review, influencing factor research, experimental teaching research, comparative research, ontology research and practical teaching research. Each number and its proportion are shown in TABLE 2. 
TABLE 2

DISTRIBUTION OF CONTENTS

\begin{tabular}{lll}
\hline Research Content & Number & \% \\
\hline Applied Research & 139 & 24.18 \\
\hline Thematic Research & 129 & 22.43 \\
\hline Investigating Research & 92 & 16.00 \\
\hline Relevance Research & 45 & 7.83 \\
\hline ESP Research & 39 & 6.78 \\
\hline Review & 33 & 5.74 \\
\hline Influencing Factor Research & 31 & 5.39 \\
\hline Experimental Teaching Research & 26 & 4.52 \\
\hline Comparative Research & 21 & 3.65 \\
\hline Ontology research & 11 & 1.91 \\
\hline Practical Teaching Research & 9 & 1.57 \\
\hline Total & 575 & 100
\end{tabular}

From TABLE 2, we can see that international translation teaching research rarely touches upon practical teaching research and ontology research. The following nine research contents will be introduced in detail.

\section{A. Applied Research}

Applied research mainly includes two aspects: the application of modern educational technology as well as teaching methods and theories.

Desjardins (2011) explores the application of social networking platform (Facebook) in translation teaching. The descriptive analysis of undergraduate courses shows that students have established a sense of realism beyond the network through collaborative translation projects and peer evaluation. Ahrenberg \& Tarvi (2013) propose applying natural language processing systems to computer-assisted translation (CAT) teaching, to calibrate and contrast different translations. Feasibility analysis proves that this system can improve the quality of students' translation. Martins, et al. (2015) study the establishment of an e-learning platform for deaf-mute students through sign language interpreters, mainly focusing on the technology integration program for sign language recognition, aiming to simplify the learning interface and content, and providing deaf-mute students with timely translation of texts and sound.

Translation teaching research rarely pays attention to the influence of translators' knowledge and beliefs on the translation process, let alone to the effect of implicit theories on the translation process. Therefore, Corbella \& León (2014) combine interview and process analysis to conduct students' translation texts, time, and correctness in order to explore the application of implicit theory in students' translation decision-making.

Way (2012) studies the application of discourse analysis in legal translator training. He believes that discourse analysis can change the form of traditional text translation teaching in classrooms, cultivate students' structured analysis process, improve their translation decision-making efficiency, enhance their ability to select legal terminology, and increase their role awareness and self-confidence as translators, Thus, translators' professional status and social recognition are found.

\section{B. Thematic Research}

Thematic research focuses on curriculum design, translation professionalism, translation skills, translation strategies, teaching assessment and translation quality, teaching models and methods, and translation ethics. Here, we mainly explore the characteristics of translation courses, translation capabilities and translation professionalism.

Translation courses are the hot topic in international translation teaching research. Scholars have elaborated on the dimensions of curriculum and curriculum evaluation. Papa \& Hafizi (2012) put forward suggestions for improving master students' oral and written translation courses: firstly, to provide students with specific course information (professional direction, employment situation, etc.) in order to help the students make choices. Secondly, to open curriculum to meet the translation enthusiasts demand. Finally, translation teachers need professional self-promotion to bridge the gap between student needs and curriculum settings. Dabaghi, et al. (2015) assesses undergraduate interpreting courses in six schools. Regarding to the problems about students with weak interpreting skills and great different interpreting quality between schools, they propose to strictly screen translate students, improve interpreting teaching materials and equipment, and attach importance to undergraduate continuous teaching for four years.

Translation ability is the core and ultimate goal of translation teaching. Popescu (2013) explores the cultivation of students' translation abilities from the perspective of linguistics, and believes that the translation abilities include language ability, social language ability, pragmatic abilities, and cross-cultural abilities. Hague (2015), based on psychology empathy, believes that audience's expectation analysis ability is an important part of the students' translation competence. To this end, he combines the PACTE model and points out that teachers need to carry out cooperative translation activities as well as to cultivate perspective taking ability to improve students' translation competence.

With the development of global information and increasing demand of translation market, translation impressionism has become a hot topic in translation teaching and research. According to Salhi (2011), in the context of translation market, translator training needs to bridge the gap between traditional translation teaching and practical translation market, and presents suggestions for corpus translation teaching as well as learning from translation experience within the United Nations system. It is noteworthy that the spread of Tibet's Buddhist culture promotes the market demand for 
Tibetan translators (Raine, 2011). In this regard, she discusses Chinese to Tibetan translation course in Chinese universities, and investigates the training courses of Tibetan translation in foreign countries. Eventually, she points out that Tibetan language translation teaching should focus on the cultivation of Tibetan language and cultural competence, and develop school training classes to meet market demand.

\section{Investigating Research}

Investigating research is to investigate the effectiveness, perception and translation process and difficulties of translation teaching through questionnaires, interviews, classroom observation, testing and thinking aloud protocols.

Rackie, et al. (2014) investigate translation effects of writing and listening in translation teaching, and study whether they exist in recall tests and recognition memory, and the relationship among these effects, memory and subjective experience. The results show that the recollection and cognitive methods are effective methods of translation teaching, and the relationship between the students' translation effect and their subjective experience is most closely related.

The perception survey mainly refers to the investigation of attitudes that include using modern educational technology and taking translation as a tool for foreign language learning. Zengin \& Kacar (2011) use semi-structured interviews, questionnaires and text analysis to investigate views of Turkey teachers on online translation tools, so as to reflect on translation practice. The study shows that participants believe that network tools play a positive role in accuracy and fluency of translation, and can improve the skills of using network tools through cooperation and learning with professional interpreters. Therefore, they suggest that we can establish translation workshops, implement in-service training and employ professional interpreters to improve the quality of translation practice.

In order to explore the ways to solve potential translation problems, Dam-Jensen (2012) uses dialogue protocols and retrospective interviews to investigate the process of peer translation test for master degree students. The results show that students can not externalize their inner thoughts, decisions and problems, or even effectively use the network or monolingual dictionary to solve translation problems. Based on these, he suggests that process analysis method should be applied to translation classroom and encourages cooperative learning to improve critical thinking and the selection of corresponding words in the process of translation.

\section{Relevance Research}

The correlation study mainly discusses the correlation between translation and language learning variables, including vocabulary, spoken language, writing, reading and listening.

Khany (2014) combines language level and gender to study the correlation between students' Lexical Cohesion Patterns (LCPs) and translation effectiveness. The results show some positive correlations. With the improvement of the language level, students' lexical cohesion patterns will be correspondingly improved and translation effect will be better. However, gender has no direct relationship with the level of vocabulary translation. The study also finds that the more complex the vocabulary is, the weaker the correlation will be between the comprehension ability of low level students and their translation ability.

Pahlavani \& Asroush (2013) select translation students to complete the Bar-On Emotional Quotient Inventory (EQi), Oral Translation test, and Oral translation scale to explore the relationship between emotional intelligence and interpreting. The research results show that there is a significantly positive correlation between interpreting and their emotional intelligence. What's more, the emotional quotients like flexibility, happiness, interpersonal relationship, independence, initiative, problem solving, self-identity, and self-realization have greater impact on the success of student interpreters.

Abbasi \& Shabani (2011) explore the relationship between writing and translation through the implementation of translation tests for students at different levels of writing. The results show that there is a correlation between the two. Therefore, they suggest that the training of students' writing and grammar should be strengthened in the teaching of translation.

Farahani \& Siyyari (2015) find there is no significant correlation between students' reading comprehension skills and translation quality through the test of Iran English literature undergraduates. Lin, et al. (2014) carry out reading and translation tests for Taiwan English majors. The results show that the improvement of students' reading ability has a positive effect on translation achievement, and the translation performance of students who read Chinese reading material is better. The study also finds that the students with different reading levels have the same ability to improve their translation. According to this, they think it is useful for students to carry out reading training before translation. In addition, mother tongue teaching may be more helpful to translation study.

Naghipoor \& Boloori (2013) explore the relevance of translation and listening. The results show that translation helps students to improve their listening comprehension.

In addition, the research on the relevance of translation ability and other factors is also the hotpots of research. Parvizi (2016) studies the relationship between self-oriented perfectionism, cultural Intelligence and translation intelligence. Based on data collection and analysis, it is concluded that there is a significant positive correlation between students' translation competence and self-oriented perfectionism, and is partly related to cultural intelligence. Based on the findings above, he suggests that students' self-oriented perfectionism and cultural intelligence can be improved through educational technology application and real text training, so as to improve students' translation competence. 


\section{E. ESP Research}

ESP (English for Special Purpose) research refers to translation teaching research in specialized purpose. Based on the literature, it is not difficult to find that the areas covered by ESP research in translation teaching mainly include: law, military, science and technology, medicine, business, multimedia, terminology, and so on.

Arslan (2015) points out that the lack of translation professionalism is the most serious issue of philosophy translation teaching. He suggests that basic philosophy courses should be offered to students majoring in translation to enable students to internalize the relevant knowledge of philosophy and improve the professionalism of students' philosophical translation. Combining with patented translation, Tarasova (2015) conducts technical translation training for Master of Engineering students, aiming to develop students' ability to understand scientific texts. Through training, students can work more efficiently on translation tasks, understand grammar knowledge, and deal with technical terminology as well as vocabulary translation based on the original style. Given that national and international security has become a hot spot in the society, Kočote \& Smirnova (2016) believe that training military translators is a very competitive advantage. For this reason, students need not only to become familiar with advanced linguistics but also to have comprehensive capabilities to solve sudden translation problems (such as the lack of equivalent terms).

\section{F. Review}

The number of review takes a few accounts and focuses on theoretical discussions. It mainly discusses the current status of translation teaching and research.

Bordenave (2012) outlines the history of translation teaching and research in Brazil, and introduces the characteristics of Brazil translation teaching.

Rogers (2010) introduces the influence of business, public services, emerging technologies and social awareness on the interpretation industry under the background of globalization, and points out challenges faced by translation teaching in universities and their countermeasures, aiming at helping future translators to form the necessary translation ability.

Through an analytical review of existing literature, Li (2014) explores the development and limitations of audiovisual translation studies, and points out that the research in the field of audiovisual translation cognition needs to be expanded. At the same time, he affirms the value of visual translation and considers the application of visual translation in the course of simultaneous interpretation. Odacioglu \& Kokturk (2015) review the development of translation technology in the 21 st century, introduce types of translation technology, and affirm the role of modern translation technology in the development of translation teaching.

\section{G. Influence Factor Research}

Influencing factor research includes direct and indirect factors. There are two direct influencing factors: (1) individual learner factors such as personal background, individual differences, and language proficiency; (2) teacher factors refer to teacher's classroom discourse. Indirect influence factors refer to the influence of various types of influence on translation students, so that they can reflect on translation teaching.

Ashouri \& Fotovatnia (2010) use the Likert scale to study the impact of risk taking and tolerance of ambiguity on translation learning. The results show that learners who support risk taking hold negative opinions on translation teaching, and ambiguity tolerance variables have no effect on translation learning. Francis, et al. (2014) investigate the effects of bilingualism and vocabulary learning on learner's translation response time, error rate, and translation effectiveness through repetition priming. According to the mixed analysis results, bilingual proficiency has a negative impact on reaction time, translation initiation and translation inequality, while vocabulary difficulty has a positive impact on response time, translation initiation, and one-way translation effects.

Teacher discourse plays an important role in the development of students' translation knowledge learning and skills. Juárez (2008) explores the role of mother-tongue teaching, the comparison of mother tongue and target language use, and students' understanding of native or target language as a learning technique. The results show that teachers' proper use of their mother tongue has a positive effect on language learning. Due to the lack of knowledge about source language and target language, students have not realized the effect of cross-language comparison on translation learning. What's more, Students affirm target language teaching environment for foreign languages but tend to use native language for translation studies.

\section{H. Experimental Teaching Research}

In experimental teaching, the researchers use method of setting the experimental group and the control group to verify the hypothesis and obtain the conclusion from the data. Common research tools include tests and questionnaires.

Kargar, et al. (2012) explore the impact of collaborative translation and explicit pragmatics teaching on the output of apologies from low-level language learners. Experimental teaching results show that the performance of the group accepting explicit pragmatic teaching is obviously better than that of the corresponding recessive group and control group. What's more, the collaborative translation group has the highest efficiency in learning pragmatic knowledge. Therefore, collaborative translation can promote the processing of students' pragmatic linguistics as well as social pragmatics knowledge and improve their practical pragmatic competence.

Mees, et al. (2013) use speech recognition (SR) software to perform two-stage experimental teaching for master 
students in three modes (view translation, translation, and SR interpretation). The data analysis results show that the students in the experimental group (SR group) are superior to the other two groups in the improvement of translation efficiency and translation quality; the retrospective interview results show that the SR software can improve students' awareness of potential speech errors and their language processing ability. This study proves the role of speech in translation teaching.

\section{Comparative Research}

Comparative research mainly involves the contrast between tradition and modernity. This includes traditional classrooms and modern classrooms, human translation and machine translation, traditional teaching methods and modern teaching methods. In addition, the comparative study also focuses on the comparison of learning effects such as translation testing, contextual translation, and subtitle translation.

Azizinezhad \& Hashemi (2011) compare the effects of traditional board writing and slide teaching in the translation classroom. The results show that traditional board writing is better than slide teaching. However, students are more satisfied with the slide course. Hemmati, et al. (2013) compares the effects of traditional translation teaching methods and translation-oriented text analysis methods on students' translation learning. According to the test results, the translation-oriented text analysis method has a positive impact on students. However, the effect of traditional translation teaching methods is not significant.

Khanmohammad \& Mohammadkhani (2009) explore the relevance of translation production test and cloze test, and compare which of the two methods better reflects the undergraduate's translation ability. The results show that the two test methods are not highly relevant, and the average grades of student paragraph translation are significantly higher than those of cloze test. Therefore, paragraph translation can measure the translation ability of undergraduate students.

\section{RESEARCH NATURE}

In international translation teaching research, scholars have adopted qualitative and quantitative research methods with numerous results. Qualitative researches include literature, case study, interview, questionnaires, comparison, and think aloud protocols. Quantitative researches include investigation, experimental teaching, think aloud protocols, process analysis, and field research. These methods can be divided into discourse study and empirical study according to the nature of research. We have conducted detailed classification and statistics on these two types of research methods (see TABLE 3).

TABLE 3

RESEARCH NATURE AND METHOD

\begin{tabular}{|c|c|c|c|c|}
\hline Research Nature & Research Method & Number & $\%$ & $\%$ \\
\hline \multirow{6}{*}{ Discourse Study } & Literature Method & 202 & 35.13 & \multirow{6}{*}{56.52} \\
\hline & Case Study & 72 & 12.52 & \\
\hline & Interview & 23 & 4.00 & \\
\hline & Questionnaire & 18 & 3.13 & \\
\hline & Comparative Method & 8 & 1.39 & \\
\hline & Think Aloud Protocols & 2 & 0.35 & \\
\hline \multirow{6}{*}{ Empirical Study } & Investigation & 210 & 36.52 & \multirow{6}{*}{43.48} \\
\hline & experimental teaching & 29 & 5.04 & \\
\hline & Think Aloud Protocols & 4 & 0.70 & \\
\hline & Process Analysis & 3 & 0.52 & \\
\hline & Interdisciplinary Research & 3 & 0.52 & \\
\hline & Field Research & 1 & 0.17 & \\
\hline Total & & 575 & 100 & 100 \\
\hline
\end{tabular}

\section{A. Discourse Study}

TABLE 3 shows that discourse study account for a relatively large amount of $56.52 \%$. The research contents mainly cover comparative research, review, thematic research, ontology research and practical teaching research. Think aloud protocols draws on psychological research and uses introspective data methods to study internal processes of translation to inspire translation teaching. Göpferich (2009) uses think aloud protocols, combined with questionnaires, interviews, and tests, conducts a three-year continuously study of the translation skills of 12 translation students, and compares this results with those of 10 professional translators, with the aim of establishing and improving of the translation ability model TransComp.

\section{B. Empirical Study}

The proportion of empirical research is relatively small, accounting for $43.48 \%$. Investigation method is the most commonly used research method, which is usually combined with questionnaires, interviews and tests to collect data and results from a statistical point of view. Pavlović (2010) uses verbal reports, records video and audio, and collects data on the process of translation for novice translators in order to ascertain the solutions that they try to adopt when interpreting problems and to classify them. After data compilation, it is found that during L1 and L2 translation process, 
the decision-making scheme they used was similar. Fattah (2017) uses field survey to collect data to study learners' vocabulary translation issues.

It is worth mentioning that some scholars begin to combine translation teaching research with cognitive neuroscience research. They use Event-related Potentials (ERPs) and functional Magnetic Resonance Imaging (fMRI) techniques to explore the complex cognitive and translation process of learners. Mayer, et al. (2015) investigate the teaching effects of two strategies: picture teaching and body language teaching in vocabulary translation learning. They use fMRI to decode the visual and cortical movements of the brain as students listen and translate. The results show that the vocabulary movements made are more effective than photo teaching while vocabulary translation learning; both strategies are better than simple vocabulary translation learning.

\section{RESEARCH BACKGROUND}

We have defined as follows: if there is only one author, the author's department or unit is the main subject; if the paper is for multiple authors, then the subject of the first author's department or unit is the basis; if the literature does not indicate the faculty or unit of the author, the journal's subject category published in the document is the main basis. Based on the classification criteria above, we find that the research background can be subdivided into 12 categories including linguistics, translation, pedagogy, computer science, communication, psychology, economics management, engineering, library and information science, physics science, cognitive science, and neuroscience (see TABLE 4).

TABLE 4

RESEARCH BACKGROUND

\begin{tabular}{lll}
\hline Research Background & Number & \% \\
\hline Linguistics & 298 & 51.83 \\
\hline Translation & 171 & 29.74 \\
\hline Pedagogy & 67 & 11.65 \\
\hline Communication & 9 & 1.57 \\
\hline Computer Science & 8 & 1.39 \\
\hline Psychology & 7 & 1.22 \\
\hline Economics Management & 6 & 1.04 \\
\hline Engineering & 3 & 0.52 \\
\hline Library and Information Science & 2 & 0.35 \\
\hline Physics Science & 2 & 0.35 \\
\hline Cognitive Science & 1 & 0.17 \\
\hline Neuroscience & 1 & 0.17 \\
\hline Total & 575 & 100 \\
\hline
\end{tabular}

From TABLE 4, we can see that the main force of international translation teaching research in the past decade is of linguistics. In the context of linguistics, we have made a detailed division, mainly including linguistics, language teaching, language and literature, cognitive linguistics, applied linguistics and other areas, which shows that the linguistic properties of translation teaching research is outstanding. The reason is that translation was originated in language courses and is an auxiliary tool for language learning. In addition, the number of researchers in the translation profession is constantly rising, which also highlights the professionalism of translation teaching research.

It is worth mentioning that a large number of interdisciplinary researchers have emerged in this research. Translation teaching research has been integrated with computer science, communication science, psychology, and economic management, enriching research contents and research perspectives. Researchers can enrich the content of translation teaching research from the perspective of interdisciplinary research and improve the scientific rigor of research.

\section{PROSPECTS FOR FUTURE RESEARCH}

We have reviewed international translation teaching research. In general, this research is mainly for undergraduates, involving a small number of doctoral students and primary and middle school students; mainly focuses on thematic research and applied research. Ontology research and ESP research are less concerned; theoretical discussion of translation teaching is another feature of international translation teaching research. At the same time, it is noticed that the proportion of empirical research is close to the discourse one, and research methods are constantly enriched. The researchers' academic backgrounds are diverse, showing the trend of interdisciplinary study.

After careful classification and discussion, we find that scholars can indeed find inspirations from international studies, as follows:

(1) The research object: to focus on the translation teaching of doctoral students or primary and middle school students, increase the research of the teacher team. A mixed study of multiple subjects should be attempted to make the research results more comprehensive.

(2) The research content: to closely follow the mainstream trend internationally, and explore factors that affect the learners' translation abilities and examine direction and employment orientation of translation professional students and translators in the context of professional translation, in order to probe into the internal relationship between translation study and language learning. Or to expand the research horizon and increase researches on the translation of sign 
language and multilingual translation.

(3) The research method: to use screen video so as to record the process of students' translation, including the speed of translation reaction, the eye tracking, etc. Through thinking aloud protocols, oral report and other introspection ways, we can fully understand the dynamic of the students in the translation process.

(4) The technical support for research: to absorb the characteristics of interdisciplinary research, and apply technology of brain science and neuroscience to translation teaching research. Using ERP, Positron Emission Tomography (PET), fMRI and other technologies to record students' thinking process in translation.

We hope this article will provide some enlightenment for the study of translation teaching, and promote a further development by expanding the research object, enriching research content, and improving research tools, making up for deficiencies in this research.

\section{REFERENCES}

[1] Abbasi, S. \& G. Shabani. (2011). The effect of proficiency in writing on EFL students' translation. In Zeng L. (Ed.), International Conference on Languages, Literature and Linguistics, Singapore: IACSIT Press, 521-525.

[2] Ahrenberg, L. \& L. Tarvi. (2013). Natural Language Processing for the Translation Class. In Erdtman E. et al. (Eds.), Proceedings of the second workshop on NLP for computer-assisted language learning at NODALIDA 2013. Linköping: Linköping University Electronic Press, 1-10.

[3] Arslan, S. (2015). The importance of the basic philosophy teaching within the framework of the translation of philosophical texts in academic translation teaching. Procedia-Social and Behavioral Sciences, 197, 759-765.

[4] Ashouri, A. F. \& Z. Fotovatnia. (2010). The effect of individual differences on learners' translation belief in EFL learning. English Language Teaching, 3(4), 228-236.

[5] Azizinezhad, M. \& M. Hashemi. (2011). Teaching translation courses, back to basics, desirable or not?. Procedia-Social and Behavioral Sciences, 28, 426-429.

[6] Bordenave, M. C. (2012). State of the art in translation teaching and research in Brazil. Tradução em Revista, 13(2), 39-43.

[7] Corbella, P. \& C. León. (2014). The role of implicit theories in the non-expert translation process. Monti Monografías De Traducción E Interpretación, nel, 273-302.

[8] Dam-Jensen, H. (2012). Decision-making in translation: a pilot study of students' translation processes. Fachesprache, 35(3), 146-164.

[9] Dabaghi, A., Moinzadeh, A. \& M. Mobasheri. (2015). Accreditation of interpreter training courses curriculum in bachelors of English translation in Iranian universities. International Journal of Applied Linguistics and English Literature, 4(6), 1-7.

[10] Desjardins, R. (2011). Facebook me!: Initial insights in favour of using social networking as a tool for translator training. Linguistica Antverpiensia, New Series-Themes in Translation Studies, 10(2), 175-193.

[11] Farahani, M. V. \& M. Siyyari. (2015). The effect of teaching reading comprehension skills on translation quality of Iranian EFL learners. International Journal of Applied Linguistics and English Literature, 4(1), 50-59.

[12] Fattah, M. H. (2017). Lexical translation problems of the Yemeni EFL learners translating multi-word verbs. Research Innovator: International Multidisciplinary Peer-Reviewed Journal, 5(1), 53-69.

[13] Francis, W. S., Tokowicz, N. \& J. F. Kroll. (2014). The consequences of language proficiency and difficulty of lexical access for translation performance and priming. Memory \& Cognition, 42(1), 27-40.

[14] Göpferich, S. (2009). Towards a model of translation competence and its acquisition: the longitudinal study TransComp. Behind the Mind: Methods, Models and Results in Translation Process Research, 4(4), 11-37.

[15] Hague, D. R. (2015). Empathic accuracy and translator training: helping students imagine other minds. The Interpreter and Translator Trainer, 9(1), 20-29.

[16] Hemmati, K., Falahati, M. A. \& H. A. Shahabi. (2013). Comparative study of traditional translation teaching method and a method based on translation-oriented text analysis in an Iranian context. The Iranian EFL Journal, 9(6), 36-49.

[17] Juárez, R. C. \& G. Oxbrow. (2008). L1 in the EFL classroom: more a help than a hindrance?. Retrieved March 20, 2018 from http://www.ugr.es/ portalin/articulos/PL_numero9/7\%20Carolina.pdf.

[18] Kargar, A. A., Sadighi, F. \& A. R. Ahmadi. (2012). The effects of collaborative translation task on the apology speech act production of Iranian EFL learners. Journal of Teaching Language Skills, 31(3), 47-78.

[19] Khanmohammad, H. \& S. A. Mohammadkhani. (2009). Comparison between the performance of Iranian EFL learners on a translation cloze test and a production test. Journal of Teaching English as a Foreign Language and Literature, 1(4), 93-110.

[20] Khany, R. (2014). Translation students' knowledge of lexical cohesion patterns and their performance in the translation of English texts. Procedia-Social and Behavioral Sciences, 98(7), 925-931.

[21] Kočote, I. \& T. Smirnova. (2016). Aspects of military-related text translation from English into Latvian. Procedia-Social and Behavioral Sciences, 231, 107-113.

[22] Li X. (2014). Sight translation as a topic in interpreting research: progress, problems, and prospects. Across Languages and Cultures, 15(1), 67-89.

[23] Lin, Y., Tseng, Y. C. \& T. Lee. (2014). From reading to translation-the effects of L1/L2 supplementary reading on Taiwanese university students' translation performance. The Asian EFL Journal Quarterly, 16(2), 222-251.

[24] Martins, P. et al. (2015). Accessible options for deaf people in e-learning platforms: technology solutions for sign language translation. Procedia Computer Science, 67, 263-272.

[25] Mayer, K. M. et al. (2015). Visual and motor cortices differentially support the translation of foreign language words. Current Biology, 25(4), 530-535.

[26] Mees, I. M., Dragsted, B. \& I. G. Hansen. (2013). Sound effects in translation. International Journal of Translation Studies, $25(1), 140-154$. 
[27] Naghipoor, M. \& L. Boloori. (2013). The role of translation tasks in foreign language listening comprehension. The Iranian EFL Journal, 9(3), 346-357.

[28] Odacioglu, M. C. \& S. Kokturk. (2015). The effects of technology on translation students in academic translation teaching. Procedia-Social and Behavioral Sciences, 197, 1085-1094.

[29] Pahlavani, P. \& M. H. Asroush. (2013). The Relationship between Emotional Intelligence (EQ) and the EFL. The Iranian EFL Journal, 9(5), 39-50.

[30] Papa, M. \& A. Hafizi. (2012). Improving the translation-interpretation curriculum through acknowledging the educational needs of Albanian students. Problems of Education in the 21st Century, 43, 69-85.

[31] Parvizi, G. R. (2016). Self-oriented perfectionism, cultural intelligence, and translation ability in Iranian EFL context. Age. Retrieved March 20, 2018 from http://www.mjal.org/Journal/current/9.pdf.

[32] Pavlović, N. (2010). What were they thinking?! Students' decision making in L1 and L2 translation processes. Hermes Journal of Language \& Communication Studies, 44, 63-87.

[33] Popescu, T. (2013). Developing English linguistics students' translation competence through the language learning process. Procedia-Social and Behavioral Sciences, 93, 1075-1079.

[34] Raine, R. (2011). Minority languages and translator training: What Tibetan programmes can tell us. The Journal of Specialised Translation, 16(2), 126-144.

[35] Rackie, J. M., Brandt, K. R. \& M. W. Eysenck. (2015). Interaction between mode of learning and subjective experience: Translation effects in long-term memory. Memory, 23(3), 318-328.

[36] Rogers, M. A. (2010). Translator and interpreter profiles: New boundaries and fuzzy edges. Cahiers de Traduction, 5, 37-47.

[37] Rokhshad, F. \& S. Ranjbar. (2016). The effect of translating Persian stories on Iranian intermediate EFL learners' speaking ability. Anglisticum Journal, 5(5), 138-147.

[38] Sachinis, M. (2011). Guest editors's introduction: Translator training: commodity or necessity? On the emergence of a new area of studies. The Journal of Specialized Translation, 16(2), 2-4.

[39] Salhi, H. (2011). Translator training in Tunisia today: Market challenges and available opportunities. Comparative Legilinguistics, 5, 35-50.

[40] Sidorenko, T., Deeva, O. \& I. Ardashkin, (2016). Technical translation for PhD programs within an English course in Russian technical universities. Procedia-Social and Behavioral Sciences, 231, 237-243.

[41] Tarasova, E. S. (2015). Technical translation teaching to the engineering students (on the example of patent descriptions). Mediterranean Journal of Social Sciences, 6(3), 350-355.

[42] Vermes, A. (2010). Translation in foreign language teaching: A brief overview of pros and cons. Eger Journal of English Studies, 10, 83-93.

[43] Way, C. (2012). A discourse analysis approach to legal translator training: More than words. International Journal of Law, Language \& Discourse, 2(4), 39-61.

[44] Zengin, B., \& Kacar I. G. (2011). Turkish EFL academicians' problems concerning translation activities and practices, attitudes towards the use of online and printed translation tools, and suggestions for quality translation practice. The Turkish Online Journal of Educational Technology, 10(2), 274-286.

Xue Li was born in Jiangsu, China. She is studying for her MA degree in the Schools of Foreign Studies of Nanjing University of Posts and Telecommunications. Her research interest includes translation teaching and research. 